\title{
Eş Zamanlı Yb ve Dy Katkılanmış CeO2 Elektrolitinin Hidrotermal Yöntem ile Sentezi ve Kristal Yapı Analizi
}

\author{
Handan ÖZLÜ TORUN ${ }^{1 *} \mathbb{D}$ \\ ${ }^{1}$ Enerji Sistemleri Mühendisliği Bölümü, Elbistan Mühendislik Fakültesi, Kahramanmaraş İstiklal \\ Üniversitesi, Kahramanmaraş, TÜRKIYE
}

Geliş / Received: 05/12/2018, Kabul / Accepted: 11/07/2019

\begin{abstract}
$\ddot{\mathbf{O} z}$
$\mathrm{Bu}$ çalışmada, farklı katkı türlerinin, farklı oranlarda seryum oksit içerisine katkılanması ile kristal yapı değişiklikleri incelenmiştir. Katkı türleri olarak lantan grubu elementi olan Yb ve Dy kullanılmıştır. Öncelikli olarak katkı miktarı \%20 olacak şekilde katkılamalar yapılmış, katkı miktarı ve katkı türüne ait yarıçap değerlerinin kristal yapı üzerinde etkisi değerlendirilmiştir. Elde edilen bulgulara göre, toplam katkı oranı \%10 düşürülmüştür. Sentez işlemlerinde hidrotermal yöntem kullanılmıştır. Sinterleme işlemleri, 300,600 ve $900{ }^{\circ} \mathrm{C}$ sıcaklıklarda gerçekleştirilerek kristal yapı aydınlatmasında ise XRD kullanılmıştır. Tanecik boyutu ve element analizi SEM-EDS ile yapılmıştır. Yapılan analiz çalışmaları neticesinde, hidrotermal yöntem ile toplam katkı oranın \%10 olan $\mathrm{Ce}_{0.9} \mathrm{Yb}_{0.05} \mathrm{Dy}_{0.05} \mathrm{O}_{2}$ bileşiğinin kübik kristal örgüye sahip olduğu bulgulanmıştır. Seramik elektrolit yapımında $\mathrm{Ce}_{0.9} \mathrm{Yb}_{0.05} \mathrm{Dy}_{0.05} \mathrm{O}_{2}$ bileşiğinin kullanılabileceği sonucuna varılmıştır.
\end{abstract}

Anahtar Kelimeler: Seramik elektrolit, hidrotermal, ikili katkılama

Synthesis of Dy and Yb Co-Doped $\mathrm{CeO}_{2}$ by Hydrothermal Method and Crystal Structure Analysis

\begin{abstract}
In this study, crystal structure changes were investigated by dope types into cerium oxide in different ratios. The lanthanum group elements, $\mathrm{Yb}$ and $\mathrm{Dy}$, were used as dope types. The contribution amount was $20 \%$, and the effect of the additive and dope type on the crystal structure was evaluated. According to the findings, the total contribution rate was reduced by $10 \%$. The hydrothermal method was used in the synthesis process. Sintering processes were carried out at 300, 600, and $900{ }^{\circ} \mathrm{C}$ temperatures and XRD were used in crystal structure determination. The particle size and element analysis were performed with SEM-EDS. As a result of the analysis studies, it was found that the total contribution rate of $\mathrm{Ce}_{0.9} \mathrm{Yb}_{0.05} \mathrm{Dy}_{0.05} \mathrm{O}_{2}$ with the hydrothermal method has a cubic crystal lattice. It was concluded that $\mathrm{Ce}_{0.9} \mathrm{Yb}_{0.05} \mathrm{Dy} \mathrm{y}_{0.05} \mathrm{O}_{2}$ compound could be used in the construction of ceramic electrolyte.
\end{abstract}

Keywords: Ceramic electrolyte, hydrothermal, co-doping

\section{Giriş}

Fosil enerji kaynaklarının tükeniyor olması ve sera gazı etkisinden dolay 1 son zamanlarda alternatif enerji arayışları dikkat çekmektedir. Yakıt hücreleri hidrojen enerjisini kullanan ve son zamanlarda sıkça karşımıza çıkan alternatif enerji kaynaklarından bir tanesidir. Tablo 1 'de görüleceği üzere yakıt hücresi içerisinde kullanan elektrolit çeşidi bakımından beş türe ayılmaktadır. Katı oksit yakıt hücreleri ise düşük sera gazı salınımı ve yüksek verimi gibi özelliklerinden dolayı geliştirilmesi gereken bir yakıt hücresi türüdür (Gómez ve Hotza, 2016; Khandkar vd., 2000; Bompard vd., 2008). 
Tablo 1.Yakıt hücresi tipleri ve kullanım alanları(Andersson, 2009)

\begin{tabular}{|c|c|c|c|c|c|}
\hline & $\begin{array}{c}\text { Alkali } \\
\text { Yakıt } \\
\text { hücresi } \\
\text { (AFC) }\end{array}$ & $\begin{array}{c}\text { Fosforik Asit } \\
\text { Yakıt Hücresi } \\
\text { (PAFC) }\end{array}$ & $\begin{array}{c}\text { Polimer } \\
\text { Elektrolit } \\
\text { Yakıt Hücresi } \\
\text { (PEMFC) }\end{array}$ & $\begin{array}{c}\text { Katı Oksit } \\
\text { Yakıt Hücresi } \\
\text { (KOYH) }\end{array}$ & $\begin{array}{c}\text { Erimiş } \\
\text { Karbonat } \\
\text { Yakıt Hücresi } \\
\text { (MCFC) }\end{array}$ \\
\hline Elektrolit & $\begin{array}{c}\text { Alkali- } \\
\text { Potasyum } \\
\text { Hidroksit }\end{array}$ & Fosforik Asit & Polimer & Seramik & $\begin{array}{c}\text { Erimiş } \\
\text { Karbonat }\end{array}$ \\
\hline $\begin{array}{c}\text { Elektrolitteki } \\
\text { Taşıyıcı }\end{array}$ & $\mathrm{OH}^{-}$ & $\mathrm{H}^{+}$ & $\mathrm{H}^{+}$ & $\mathrm{O}_{2}{ }^{-2}$ & $\mathrm{CO}_{3}{ }^{-2}$ \\
\hline Yakıt Türü & $\mathrm{H}_{2}$ & $\begin{array}{c}\mathrm{H}_{2}, \\
\text { Hidrokarbonlar, } \\
\text { Fosil yakıtlar }\end{array}$ & $\begin{array}{c}\mathrm{H}_{2}, \\
\text { Hidrokarbonlar }\end{array}$ & $\begin{array}{c}\mathrm{H}_{2}, \\
\text { Hidrokarbonlar }\end{array}$ & $\begin{array}{c}\mathrm{H}_{2}, \\
\text { Hidrokarbonlar }\end{array}$ \\
\hline $\begin{array}{l}\text { Çalışma } \\
\text { Sıcaklığı }\end{array}$ & $50-200^{0} \mathrm{C}$ & $\sim 220^{\circ} \mathrm{C}$ & $70-100^{0} \mathrm{C}$ & $500-1000^{\circ} \mathrm{C}$ & $\sim 650^{\circ} \mathrm{C}$ \\
\hline $\begin{array}{l}\text { Güç Üretim } \\
\text { Verimi }(\%)\end{array}$ & $45-60$ & $45-65$ & $40-70$ & $45-75$ & $50-65$ \\
\hline $\begin{array}{l}\text { Uygulama } \\
\text { Alanları }\end{array}$ & $\begin{array}{c}\text { Uzay, } \\
\text { sabit güç }\end{array}$ & $\begin{array}{l}\text { Kojenerasyon, } \\
\text { sabit güç, } \\
\text { taşıma }\end{array}$ & Uzay, taşıma & $\begin{array}{l}\text { Kojenerasyon, } \\
\text { sabit güç, ticari } \\
\text { ve sanayi } \\
\text { uygulamaları }\end{array}$ & $\begin{array}{l}\text { Kojenerasyon, } \\
\text { sabit güç }\end{array}$ \\
\hline
\end{tabular}

Şekil 1'de görüleceği üzere katı oksit yakıt hücreleri kimyasal enerjiyi doğrudan elektrik enerjisine çeviren sistemlerdir. Basit olarak yapilarında anot, katot elektrotu ve elektrolitten oluşur. Bir katı oksit yakıt hücresininen önemli bileşeni yoğun seramik elektrolitidir. Elektrolit olarak kullanılacak bileşik, oksijen iyonik iletkenliği göstermeli, kararlı olmalı ve diğer bileşenler ile kimyasal reaksiyona girmemelidir. Günümüzde8YSZ elektroliti, en çok bilinen ve çalışılan seramikelektrolittir. Ancak, 8YSZ $1000{ }^{\circ} \mathrm{C}$ üzerinde yüksek oksijen iyonik iletimi göstermektedir. $\mathrm{Bu}$ sicaklık ise hücre maliyetini yükseltmekte ve yakıt hücresinin diğer bileşenlerinin bozulmasına sebep olmaktadır. $\mathrm{ZrO}_{2}$ tabanlı elektrolitlere alternatif olarakCeO $\mathrm{C}_{2}$ elektrolitleri sahip oldukları florit yapılı kristal örgüsü ile oksijen iyonik iletkenliği göstermektedir. Ve çalışma sicaklığını $\quad 550-800 \quad{ }^{\circ} \mathrm{C} \quad$ aralığına indirebilmektedir (Mahato vd.,2015; Badwal ve Foger, 1996; Goodenough, 2003; Shuk vd., 1996).

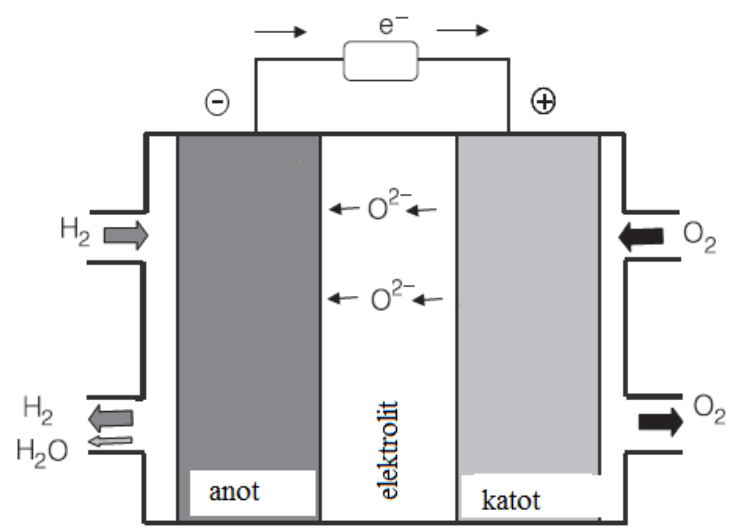

Şekil 1. Katı oksit yakıt hücresi bileşenleri

$\mathrm{CeO}_{2}$ 'in seramik elektrolit olarak kullanılabilmesi için kristal yapısının florit yapıda olması gerekmektedir. Şekil 2'de saf $\mathrm{CeO}_{2}$ ve katkılanmış $\mathrm{CeO}_{2}$ kristal yapıları görülmektedir. Florit yapı elde edilmesinde ve iletkenliğini iyileştirmede katkı maddesi türü, miktarı, yarıçapı, sentez şartları etkilidir. 
Şimdiye kadar $\mathrm{CeO}_{2}$ içerisine farklı bileşikler değişik oranlarda katkılanarak çalışılmıştır (Chou vd., 2013; Mendiuk vd., 2016; Cesario vd., 2016; Anjeneya vd., 2013; Steele, 2000; Stambouli ve Traversa, 2002).

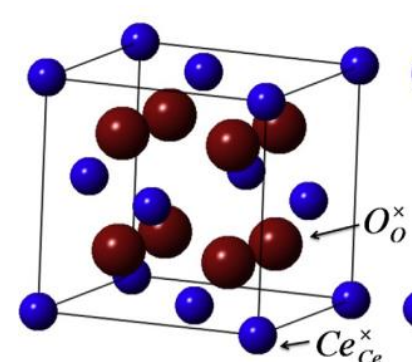

(a)

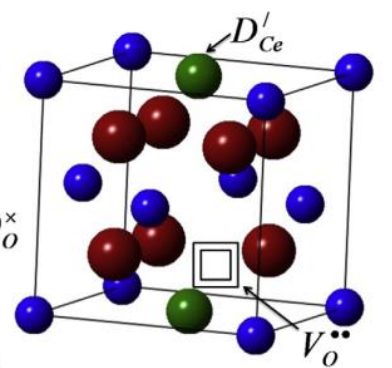

(b)
Şekil 2. (a) Ce ait kristal yapı (b) Katkılanmış $\mathrm{Ce}$ içerisinde oksijen iyonu boşluğu (Stambouli ve Traversa, 2002)

Şimdiye kadar yapılan çalışmalarda Gd ve Sm katk1lı kübik kristal örgülü $\mathrm{CeO}_{2}$ bileşiğinin iletkenliğinin yüksek olduğu bulunmuştur. Ancak, son zamanlarda ikili katkılamalar kullanılarak iletkenliğin tek tür katkılamalara göre iletkenlik derecesinin \%10-15 arasında iyileştirildiği görülmüştür. $\mathrm{CeO}_{2}$ seramik elektroliti üretilirken katkı aralığının \%1-20 aralığında olması gerektiği, yüksek oranlarda katkılama yapmanın hücre içerisinde gerginliği artırdığı, iletkenlik değerini düşürdüğü bulgulanmıştır. Yarı çap1 Ce katyonundan yüksek olan iyonlar kristal örgüde oksijen iyonlarının hareket edebileceği boşluk oranını artıracağından iletkenliği artırmaktadır (Moure vd., 2012; Wang vd., 2016; Kahlaoui vd., 2013; Ramesh ve Raju, 2012; Madhusudan vd., 2018).

Kübik yapılı seramik elektrolit elde edilmesinde farklı sentez yöntemleri kullanılmaktadır. En çok kullanılan sentez yöntemleri, klasik katı hal, glisin nitrat, solgel, hidrotermal, birlikte çöktürme, ultrasonik, mikrodalga ile çözme teknikleridir (Madhusudan vd., 2018; Arabac1 ve Öksüzömer, 2012; Ozlu vd., 2014). Seçilen yönteme göre başlangıç bileşikleri değişmektedir. Örneğin klasik katı hal yönteminde katyonların oksitli bileşikleri kullanılırken, sol-jel yönteminde nitrat/hidrat içeren bileşikleri kullanılır. Ayrıca, kullanılan sentez yöntemine göre de düşük tanecik boyutlu üretim yapabilen yöntem yüzey alanını artıracağından iletkenlik üzerine olumlu etkisi olmaktadır Seçilen yöntemin maliyet, zaman ve verim, açısından en uygun olanı tercih edilmelidir. Klasik katı hal sentezinde kristal boyut 90 angström iken hidrotermal yöntemde aynı bileşik için 54 angströmdür (Kim vd., 2013). Hidrotermal yöntem ile kısa sürede nano boyutlu tanecikler edilebilmektedir. Hidrotermal yöntemle yapılan sentez işlemleri genel olarak şu şekilde tanımlanabilir; $100{ }^{\circ} \mathrm{C}$ üzerinde ve 1 atm basınçtan daha yüksek basınçta sulu ortamda gerçekleştirilen reaksiyonlardır. Reaksiyon sonucu elde edilen bileşiklerin tanecik boyutu nano düzeye kadar inebilmektedir (Kerli vd., 2013; PanahiKalamuei vd., 2015).

$\mathrm{Bu}$ çalışmada, yukarıda verilen bilgiler 1şığında iki farklı lantan grubu element eş zamanlı olarak kısa süreli hidrotermal yöntem kullanılarak $\mathrm{CeO}_{2}$ içerisine katkılanmıştır. Katkı türleri ile ilgili oranlar ve deney şartları literatürden farklılık göstermektedir. Katkılamada farklı mol oranları ve sentez isıl işlem adımları ile kübik kristal örgüye sahip toz $\mathrm{CeO}_{2}$ bileşiği elde edilmeye çalışılarak bu faktörlerin etkisi incelenmiştir.

\section{Materyal ve Metot}

Seramik elektrolit; $\quad \mathrm{Ce}_{1-2 \mathrm{x}} \mathrm{Dy}_{\mathrm{x}} \mathrm{Yb}_{\mathrm{x}} \mathrm{O}_{2}$ hidrotermal yöntem kullanılarak sentezlenmiştir. Sentez işlemleri için başlangıç malzemeleri olarak $\left(\mathrm{Dy}\left(\mathrm{NO}_{3}\right)_{3} .5 \mathrm{H}_{2} \mathrm{O}\right)$ (Alfa Aesar, \%99.9), $\left(\mathrm{Yb}\left(\mathrm{NO}_{3}\right)_{3} .5 \mathrm{H}_{2} \mathrm{O}\right) \quad$ (Aldrich, \%99.9), $\left(\mathrm{Ce}\left(\mathrm{NO}_{3}\right)_{3} .6 \mathrm{H}_{2} \mathrm{O}\right)$ (Alfa Aesar \%99.9) kullanılmıştır. İstenen yüzdeliklerde tartımlar gerçekleştirildikten sonra beherde içerisinde $75 \mathrm{ml}$ saf suda çözme işlemi yapılmıştır. Manyetik karıştırıcı üzerinde karıştırma işlemine devam edilen berrak çözelti içerisine önceden hazırlanan $6 \mathrm{M} \mathrm{NaOH}$, yaklaşık 30 
dakika boyunca çökmeler tamamlanıncaya kadar damla damla eklenmiş̧tir. Çökelme işlemi tamamlanınca teflon kap içerisine alınan krem renkli heterojen çözelti, hidrotermal işlem için çelik hazne içerisine yerleştirilerek kapak sıkıca kapatılmıştır. Hidrotermal işlem sıcaklık $180^{\circ} \mathrm{C}$, süre ise 12 saat olacak şekilde gerçekleştirilmiştir. Isıl işlem sonrasında teflon kap içerisinden alınan örnek süzgeç kâğıdında süzme işlemi sonrasında saf su ile $3 \mathrm{kez}$ yıkanarak bir gece oda sıcaklığında kurutulmuştur. Kurutma sonrası süzgeç kağıdından alınan toz örnekler agat havanda yaklaşık olarak 10 dakika el ile ögütülmüştür. Toz örnekler alümina kroze içerisine alınarak sırayla $300{ }^{\circ} \mathrm{C}, 600{ }^{\circ} \mathrm{C}$ ve $900^{\circ} \mathrm{C} 18$ saat 1 sil işleme tabi tutulmuştur. Her bir 1 sıl işlem sonrasında ara öğütmeler yapılarak ve XRD analizi için toz örnekler alınmıştır.

Karakterizasyon çalışmalarında; Toz elektrolitin kristal yapıları Panalitik Empyrean X-ray difraktometre üzerinde araştırıld. Kristal büyüklüğü Scherrer denklemi kullanılarak hesaplandı. X'Pert High Score Plus yazilımı kullanıldı. Örneklerin yüzey morfolojisi araştırmalarında Zeiss EVO 10LS marka taramalı elektron mikroskobu kullanıldı. Element analizlerinde ise EDS kullanıldı.

\subsection{Kristal Yapı Aydınlatması}

$\mathrm{X}$-ışınımı kırınım yöntemi, her bir kristalin fazın kendine özgü atomik dizilimine bağlı olarak x-1̧̧ınlarını karakteristik bir düzen içerisinde kırması esasına dayanır. Her bir kristal faz için parmak izi niteliğindedir. XRD ölçümleri sonrasinda ICSD kütüphaneden yararlanarak, sentezlenen tozların kristal örgüsü tespit edilebilmektedir. Şekil 3'de toplam katkı türü miktarı $\% 20$ olarak yapılan hidrotermal sentez işlemi sonrasında toz örneklere ait n XRD deseni görülmektedir. $\mathrm{Ce}_{0.8} \mathrm{Yb}_{0.1} \mathrm{Dy}_{0.1} \mathrm{O}_{2}$ toz örneğin $300{ }^{\circ} \mathrm{C} 18$ saat ısıl işlem sonrasında seramik elektrolit için beklenen kübik yapının oluşmadığı gözlendi. $600{ }^{\circ} \mathrm{C}$ ve $900{ }^{\circ} \mathrm{C} 18$ saat yapılan isıl işlem ve ara ögütmeler sonrasında $\% 20$ katk1 oranı ile saf kübik kristal yapı elde edilememiş̧ir.

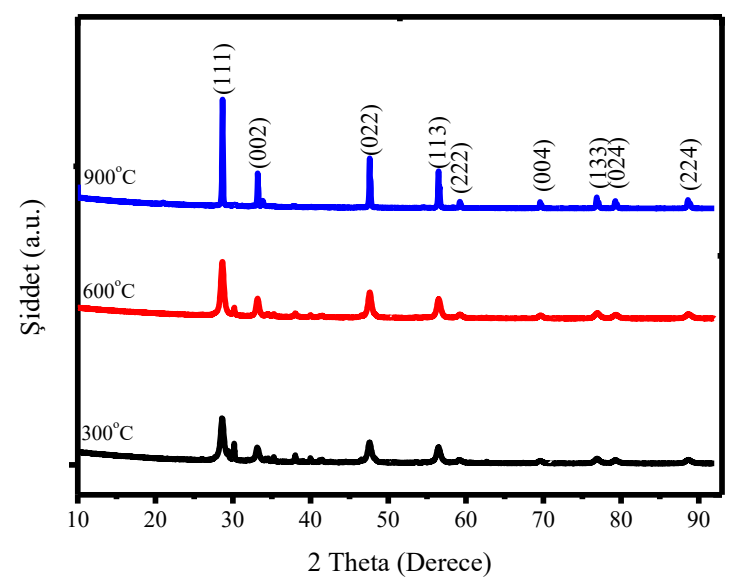

Şekil 3.Farkl1 sicaklıklarda $\mathrm{Ce}_{0.8} \mathrm{Yb}_{0.1} \mathrm{Dy}_{0.1} \mathrm{O}_{2}$ ait XRD toz deseni

$\mathrm{CeO}_{2}$ kübik kristal örgüye sahip seramik formunu elde edebilmek için katkı türlerinin $\%$ mol oranı düşürülerek ssıl işlem ve ögütme basamakları tekrarlanmıştır. Toplam katkı oran $1 \% 10$ olan $\mathrm{Ce}_{0.9} \mathrm{Yb}_{0.05} \mathrm{Dy}_{0.05}$ toz örneğin, Şekil 4'de görüldüğü gibi $300{ }^{\circ} \mathrm{C} 18$ saat ${ }_{1 s 1}$ işlemden itibaren kübik kristal örgülü toz seramik elektrolit elde edilmiştir.(ICSD No:98-015-7419).

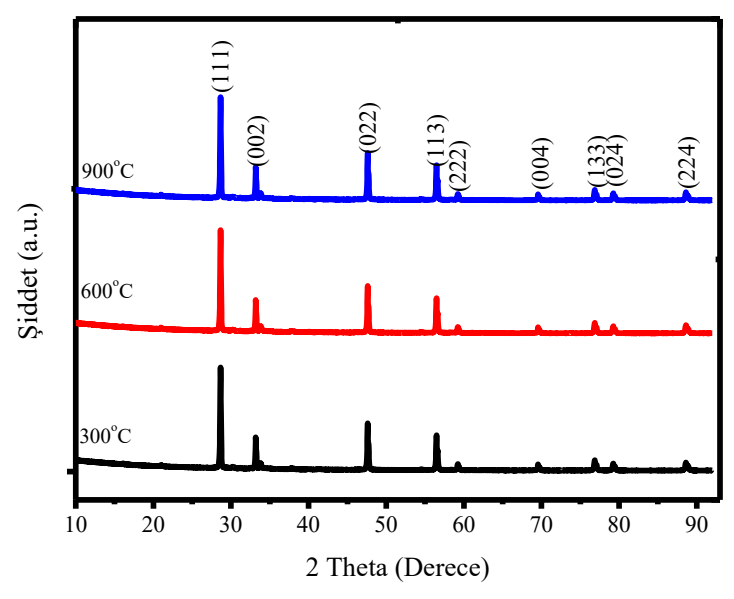

Şekil 4. Farklı sicaklıklarda $\mathrm{Ce}_{0.9} \mathrm{Yb}_{0.05} \mathrm{Dy}_{0.05} \mathrm{O}_{2}$ ait XRD toz deseni 
Tablo 1' de ise $300{ }^{\circ} \mathrm{C}, 18$ saat 1 sıl işlem $\theta$ değerleri ayrıntıları görülebilmektedir. $\% 20$ sonrası yapılan XRD analizi değerlendirme mol oranında kristal yapı elde sonuçlarına göre kübik kristal örgüye sahip edilemediğinden bu bileşiğe ait sonuçlara yer $\mathrm{CeO}_{2}$ 'in piklerinin şiddeti, bağıl şiddeti, $d$ ve verilmemiştir.

Tablo 1. $\mathrm{Ce}_{0.8} \mathrm{Yb}_{0.1} \mathrm{Dy}_{0.1} \mathrm{O}_{2} 300{ }^{\circ} \mathrm{C} 18$ saat sonras1 $\mathrm{XRD}$ verileri

\begin{tabular}{ccccccc}
\hline $\begin{array}{c}\text { Açı } \\
{\left[{ }^{\circ} \mathrm{O}\right]}\end{array}$ & $\begin{array}{c}\text { Yükseklik } \\
{[\mathrm{cts}]}\end{array}$ & $\begin{array}{c}\text { FWHM } \\
{\left[{ }^{\circ} 2 \mathrm{O}\right]}\end{array}$ & $\mathrm{d}-[\AA]$ & $\begin{array}{c}\text { Bağ1l } \\
\text { Şiddet } \\
{[\%]}\end{array}$ & $\begin{array}{c}\text { Pik } \\
\text { Genişliği }\end{array}$ & ICSD \\
\hline 28.5258 & 9583.32 & 0.3838 & 3.12658 & 100.00 & 0.4605 & $98-015-7419$ \\
33.0324 & 2766.50 & 0.2303 & 2.70959 & 28.87 & 0.2763 & $98-015-7419$ \\
47.4933 & 4800.14 & 0.3582 & 1.91287 & 50.09 & 0.4298 & $98-015-7419$ \\
56.2437 & 3182.88 & 0.3582 & 1.63425 & 33.21 & 0.4298 & $98-015-7419$ \\
59.0901 & 593.15 & 0.4093 & 1.56213 & 6.19 & 0.4912 & $98-015-7419$ \\
69.4075 & 534.66 & 0.6652 & 1.35298 & 5.58 & 0.7982 & $98-015-7419$ \\
76.6657 & 1037.46 & 0.2558 & 1.24196 & 10.83 & 0.3070 & $98-015-7419$ \\
79.0827 & 680.76 & 0.3326 & 1.20995 & 7.10 & 0.3991 & $98-015-7419$ \\
88.3594 & 837.41 & 0.3582 & 1.10530 & 8.74 & 0.4298 & $98-015-7419$ \\
\hline
\end{tabular}

Elde edilen toz seramik elektrolitlerin sıcaklığa bağlı olarak kristal yapı değişiklikleri analiz edilmiştir. Kristal büyüklüğü ve kristal gerilmeleri hesaplamalarında Debye-Scherrer eşitliğinden kullanılmıştır. Debye-Scherrer hesaplamalarında en yüksek şiddete sahip üç pik (111), (022) ve (133) kullanılmıştır. Kristal büyüklüğü ve kristal değerleri aritmetik ortalamalar alınmıştır.

$D=\frac{0.89 \lambda}{\beta \cos \theta} \beta=\beta o b s-\beta s t d$

$\varepsilon=\frac{\beta}{4 \tan \theta} \quad \beta=\sqrt{\beta o b s^{2}-\beta s t d^{2}}(1.2)$

$\mathrm{Bu}$ denklemlerde $\mathrm{D}$ kristal büyüklüğünü, $\lambda$ kullanılan X-1şınının dalga boyunu $(\mathrm{Cu} \mathrm{K \alpha}$ 1.5418), $\beta$ pik yarı yüksekliğinin genişliği (FWHM), $\theta$ Bragg açısını ve $\varepsilon$ kristal gerilmesini ifade etmektedir. Cihazdan kaynaklanan hataların minimize edilmesi için silikon standart kullanılarak FWHM değerleri belirlenecek ve yukarıdaki denklemde yerine konuldu. Elde edilen sonuçlar Tablo 2'de görülmektedir. 
Tablo 2. $\mathrm{Ce}_{0.9} \mathrm{Yb}_{0.05} \mathrm{Dy}_{0.05} \mathrm{O}_{2}$ toz örneğinin kristal yapı değerleri

\begin{tabular}{|c|c|c|c|c|c|c|c|}
\hline \multirow[t]{2}{*}{ Örnek } & \multirow{2}{*}{$\begin{array}{c}\begin{array}{c}\text { Birim } \\
\text { Hücre } \\
\text { Parametresi }\end{array} \\
\mathrm{a}(\AA)\end{array}$} & \multirow[t]{2}{*}{$\begin{array}{l}\text { Uzay } \\
\text { Grubu }\end{array}$} & \multirow{2}{*}{$\begin{array}{r}\text { Hacim } \\
(\AA)^{3}\end{array}$} & \multicolumn{4}{|c|}{$\begin{array}{c}\text { Kristal } \\
\text { Boyutu } \\
(\mathrm{nm})\end{array}$} \\
\hline & & & & $\begin{array}{r}\text { Ana } \\
\text { değer }\end{array}$ & (111) & $(022)$ & (113) \\
\hline $\begin{array}{c}\mathrm{Ce}_{0.9} \mathrm{Yb}_{0.05} \mathrm{Dy}_{0.05} \mathrm{O}_{2} \\
\left(300{ }^{\circ} \mathrm{C}\right)\end{array}$ & 5.4164 & $\begin{array}{r}\text { Fm- } \\
3 \mathrm{~m}\end{array}$ & 158.84 & 22.54 & 21.26 & 24.42 & 25.42 \\
\hline $\begin{array}{c}\mathrm{Ce}_{0.9} \mathrm{Yb}_{0.05} \mathrm{Dy}_{0.05} \mathrm{O}_{2} \\
\left(600{ }^{\circ} \mathrm{C}\right)\end{array}$ & 5.4142 & $\begin{array}{r}\text { Fm- } \\
3 \mathrm{~m}\end{array}$ & 158.71 & 25.10 & 26.42 & 25.07 & 22.38 \\
\hline $\begin{array}{c}\mathrm{Ce}_{0.9} \mathrm{Yb}_{0.05} \mathrm{Dy}_{0.05} \mathrm{O}_{2} \\
\left(900{ }^{\circ} \mathrm{C}\right)\end{array}$ & 5.4072 & $\begin{array}{r}\text { Fm- } \\
3 \mathrm{~m}\end{array}$ & 158.09 & 57.62 & 67.6 & 49.78 & 38.57 \\
\hline
\end{tabular}

Kübik kristal örgüye sahip $\mathrm{CeO}_{2}$ örgü parametresi a $=0.541 \mathrm{~nm}$ 'dir[Omar vd., 2009). $300{ }^{\circ} \mathrm{C} 18$ saat 1 sil işlem sonrası oluşan toz seramik elektrolitin kristal örgü parametresinde artış gözlendi. $\mathrm{Bu}$ artışın temel nedeni katk1 türlerinin iyonik yarıçaplarının $\mathrm{Ce}^{4+}$ 'den büyük olmasından kaynaklanmaktadır. $\mathrm{Ce}^{4+}$ iyonik yarıçapı $0.967 \AA, \mathrm{Dy}^{3+}$ iyonik yarıçapı $1.053 \AA$ ve $\mathrm{Yb}^{3+}$ için iyonik yarıçap değeri 0.985 $\AA ̊$ 'dur[Database of ionic radii,2018]. Kristal örgüde $\mathrm{Ce}^{4+}$ yerine $\mathrm{Dy}^{3+}$ ve $\mathrm{Yb}^{3+}$ yerleşir. Kristal boyutlar 22-57 $\mathrm{nm}$ aralığında değişmektedir. Seramik elektrolitler için kristal boyut önemlidir. Kristal boyutunun düşük olmasının iletkenlik üzerine olumlu yönde etkisi bulunmaktadır.

\subsection{Yüzey Analiz}

Toz formunda 300 ve $900 \quad{ }^{\circ} \mathrm{C}$ $\mathrm{Ce} 0 .{ }_{9} \mathrm{Yb}_{0.05} \mathrm{Dy}_{0.05} \mathrm{O}_{2}$ örneklerinin yüzey analiz görüntüleri ve EDS sonuçları Şekil 5, 6 ve 7' de verilmiştir. Şekil $5^{\prime}$ te $300^{\circ} \mathrm{C}$ de 1 sıl işlem görmüş örneğin tanecik boyutları 60-100 nm arasında değiştiği görülmüştür. Öğütme sonrasında $900{ }^{\circ} \mathrm{C}$ ssıl işleme tabi tutulan örneğin Şekil 6' da görülebileceği üzere ise tane boyutlarının 200-450 nm arasında değiştiği bulgulanmıştır.

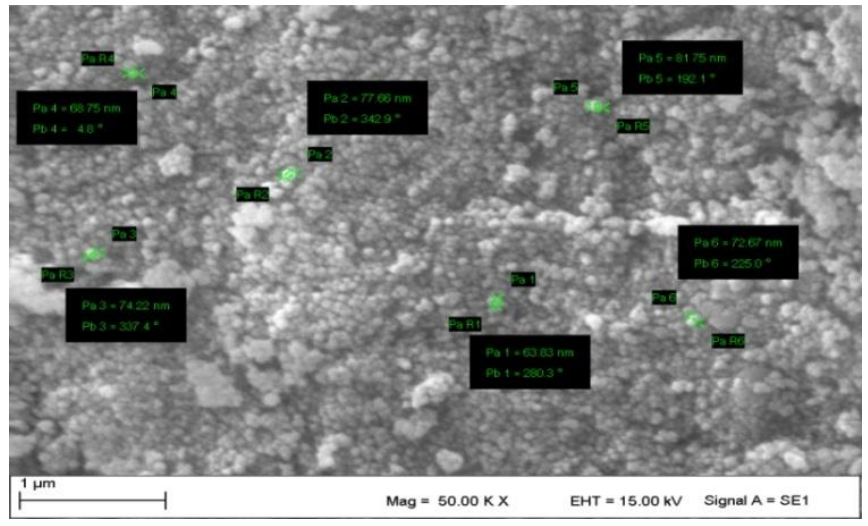

Şekil 5. $300 \quad{ }^{\circ} \mathrm{C} \quad 1$ sıll işlem görmüş $\mathrm{Ce}_{0.9} \mathrm{Yb}_{0.05} \mathrm{Dy}_{0.05} \mathrm{O}_{2}$ örneğinin yüzey analiz görüntüsü.

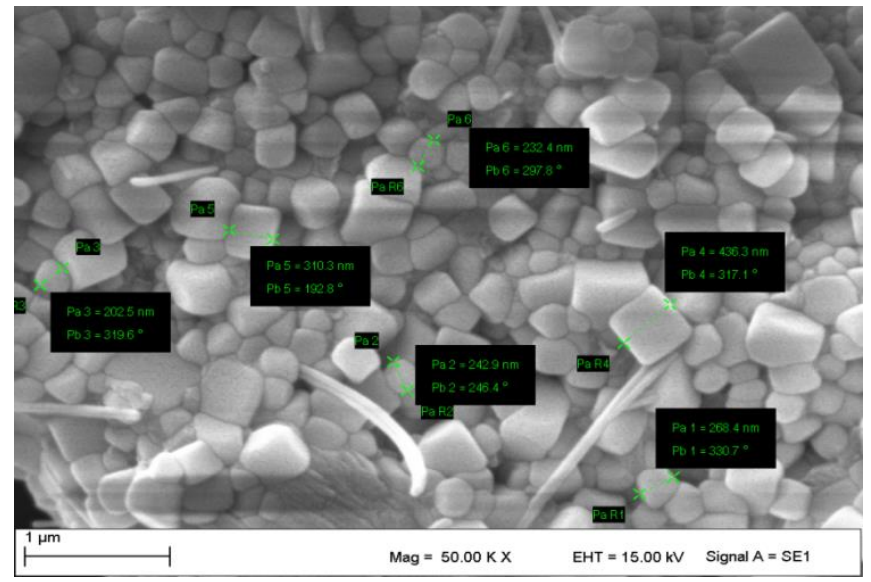

Şekil 6. $900 \quad{ }^{\circ} \mathrm{C} \quad$ 1sil işlem görmüş $\mathrm{Ce}_{0.9} \mathrm{Yb}_{0.05} \mathrm{Dy}_{0.05} \mathrm{O}_{2}$ örneğinin yüzey analiz görüntüsü 
Isıl İşlem tane boyutunu büyüttüğü görülmüştür. Sicaklık faktörü ile difüzyon hızı artmaktadır. Küçük boyutlu tanecikler bir arya gelerek daha büyük tane boyutlu yapılar oluşmaktadır.

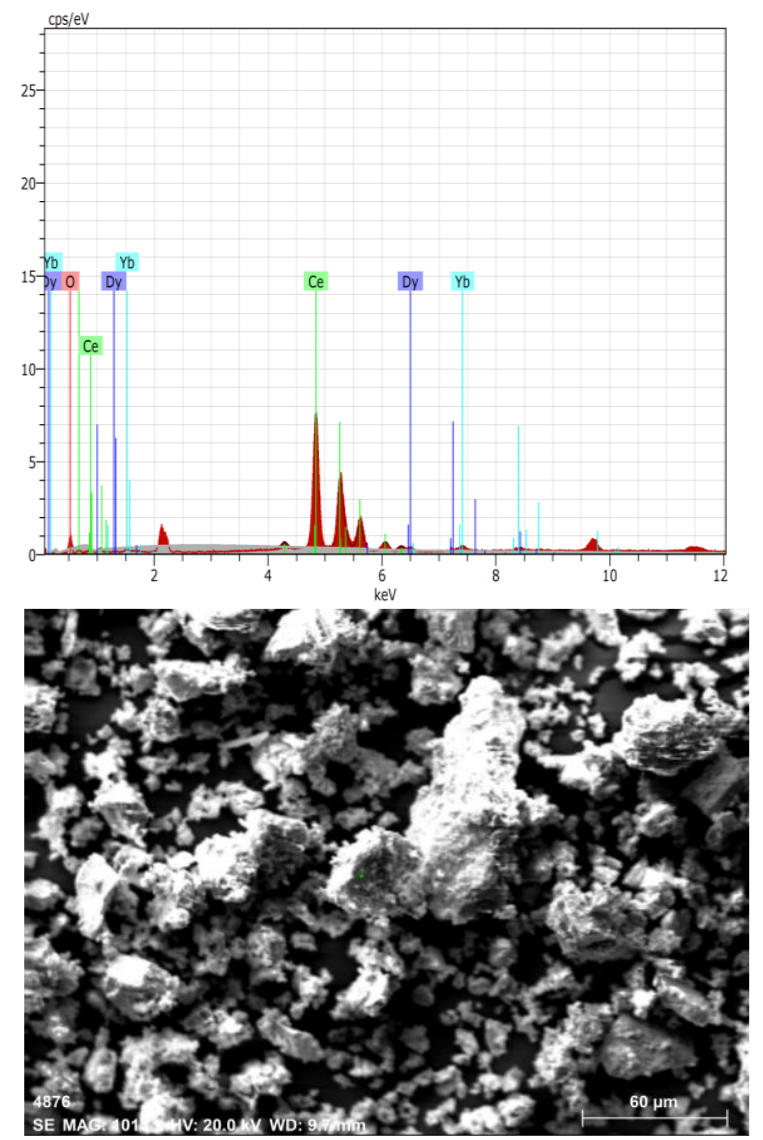

Şekil 7. $\mathrm{Ce}_{0.9} \mathrm{Yb}_{0.05} \mathrm{Dy}_{0.05} \mathrm{O}_{2}$ örneğinin $\mathrm{EDS}$ analizi

EDS sonuçlarına göre kristal yapıda Ce, Dy, $\mathrm{O}$ ve $\mathrm{Yb}$ atomları görülmüştür. Kaplamadan kaynaklı Au pikleri de mevcuttur. Ağırlıkça oran olarak başlangıç stokiyometrisine yakın oranlar görülmüştür.

\section{Sonuç ve Tartışma}

$\mathrm{Bu}$ çalışmada, seryum kristal yapısı üzerine sıcaklık, katkı türü ve miktarının etkisi incelenmiştir. Yapılan hidrotermal sentez işlemleri sonucunda katkı türü olarak seçilen $\mathrm{Yb}$ ve Dy atomlarının toplam katkı miktarının \%20 olması kübik yapının oluşmasını engellemiştir. Sıcaklık basamaklarının kademeli olarak artırılması, kristal yapıda iyileşmeye sebep olsa da yeterli gelmemiştir. Kübik yapının oluşabilmesi için $\mathrm{Yb}$ ve Dy toplam katk1 aralığı \%10 düşürülmüş ve böylece istenilen kristal yapının düşük sıcaklıklardan itibaren elde edildiği bulgulanmıştır. SEM-EDS sonuçlarına göre 1sıl işlemin tane boyutlarını artırdığı gözlenmiştir. Kristal yapının Ce, Dy, Yb ve O atomlarından oluştuğu tespit edilmiştir. Hidrotermal yöntem ile kübik kristal örgüye sahip seramik toz elektrolitler başarılı bir şekilde sentezlenmiş ve $300{ }^{\circ} \mathrm{C}$ den itibaren nano boyutlu kristal örgüye sahip malzemeler elde edilmiştir. Mevcut sonuçlar ile $\mathrm{Ce}_{0.9} \mathrm{Yb}_{0.05} \mathrm{Dy}_{0.05} \mathrm{O}_{2}$ seramik elektrolit olarak kullanılabilir özelliktedir.

\section{Teșekkür}

$\mathrm{Bu}$ çalışmada destek veren KSÜ Elbistan Teknoloji Fakültesine teşekkür ederim.

\section{Kaynaklar}

Andersson, M. (2009). "SOFC modeling considering mass and heat transfer, fluid flow with internal reforming reactions". Lund University.

Anjaneya, K. C., Nayaka, G. P., Manjanna, J., Govindaraj, G., Ganesha, K. N. (2013). "Preparation and characterization of $\mathrm{Ce}_{1-} \mathrm{Gd}_{\mathrm{x}} \mathrm{O}_{2-} \delta(\mathrm{x}=$ $0.1-0.3)$ as solid electrolyte for intermediate temperature SOFC", Journal of Alloys and Compounds, 578, 53-59.

Arabac1, A., Öksüzömer, M. F. (2012). "Preparation and characterization of $10 \mathrm{~mol} \%$ Gd doped $\mathrm{CeO}_{2}$ (GDC) electrolyte for SOFC applications", Ceramics International, 38(8), 6509-6515.

Badwal, S. P. S., Foger, K. (1996). "Solid oxide electrolyte fuel cell 
review", Ceramics

International, 22(3), 257-265.

Bompard, E., Napoli, R., Wan, B., Orsello, G. (2008). "Economics evaluation of a $5 \mathrm{~kW}$ SOFC power system for residential use", International Journal of Hydrogen Energy, 33(12), 3243-3247.

Cesário, M. R., Savary, E., Marinel, S., Raveau, B., Caignaert, V.(2016). "Synthesis and electrochemical performance of $\mathrm{Ce}_{1-} \mathrm{Yb}_{\mathrm{x}} \mathrm{O}_{2-\mathrm{x} / 2}$ solid electrolytes: The potential of microwave sintering", Solid StateIonics, 294, 67-72.

Chou, C. C., Huang, C. F., Yeh, T. H. (2013). "Investigation of ionic conductivities of $\mathrm{CeO}_{2}$-based electrolytes with controlled oxygen vacancies", Ceramics

International, 39, S627-S631.

Database of ionic radii,(2018), http://abulafia.mt.ic.ac.uk/shannon/pt able.php

Gómez, S. Y., Hotza, D. (2016). "Current developments in reversible solid oxide fuel cells", Renewable and Sustainable EnergyReviews, 61, 155174.

Goodenough J. B. (2003). "Oxide-ion electrolytes. Annual review of materials research", 33(1), 91-128.

Kahlaoui, M., Chefi, S., Inoubli, A., Madani, A., Chefi, C. (2013)" Synthesis and electrical properties of co-doping with $\mathrm{La}^{3+}, \mathrm{Nd}^{3+}, \mathrm{Y}^{3+}$, and $\mathrm{Eu}^{3+}$ citric acidnitrate prepared samarium-doped ceria ceramics", Ceramics

International, 39(4), 3873-3879.

Khandkar, A., Hartvigsen, J., Elangovan, S.(2000). "A techno-economic model for SOFC power systems", Solid State Ionics, 135(1-4), 325-330.

Kerli, S., Alver, U., Yaykasli, H., Avar, B., Tanriverdi, A.,Kursun, C. (2013)." Synthesis of Fluorine Doped Zinc Oxide Particles by Hydrothermal Method", Asian Journal of Chemistry, 25(13), 7539.

Kim, G., Lee, N., Kim, K. B., Kim, B. K., Chang, H., Song, S. J., Park, J. Y. (2013). "Various synthesis methods of aliovalent-doped ceria and the irelectrical properties for intermediate temperature solid oxide electrolytes", International Journal of Hydrogen Energy, 38(3), 1571-1587.

Mahato, N., Banerjee, A., Gupta, A., Omar, S., Balani, K. (2015). "Progress in material selection for solid oxide fuel cell technology: A review." Progress in Materials Science, 72, 141-337.

Madhusudan, C., Kasarapu, V., Chittimadula, M., Reddy, Y. S., Reddy, C.V.(2018) "Synthesis and characterization of $\mathrm{Y}$ and Dy co-doped ceria solid electrolytes for IT-SOFCs: a microwave sintering" RareMetals, 18.

Mendiuk, O., Nawrocki, M., Kepinski, L.(2016). "The synthesis of $\mathrm{Ce}_{1-}$ ${ }_{\mathrm{x}} \mathrm{Ln}_{\mathrm{x}} \mathrm{O}_{2-}$ y $(\mathrm{Ln}=\mathrm{Pr}, \mathrm{Sm}, \mathrm{Gd}, \mathrm{Tb})$ nanocubes by hydrothermal methods", Ceramics International, 42(1), 19982012.

Moure, A., Castro, A., Martinez, I., Moure, C., Tartaj, J. (2012). "Synthesis, sintering and ionic conductivity of scandia-doped ceria ceramic materials obtained by different procedures", Ceramics International, 38(7), 5907-5914.

Omar, S., Wachsman, E. D., Jones, J. L., Nino, J. C. (2009). "Crystal structure- 
ionic conductivity relationships in doped ceria systems", Journal of the American Ceramic Society,92(11), 2674-2681

Ozlu, H., Cakar, S., Bilir, C., Ersoy, E.,Turkoglu, O. (2014). "Synthesis and characterization of $\gamma-\mathrm{Bi}_{2} \mathrm{O}_{3}$ based solid electrolyte doped with $\mathrm{Nb}_{2} \mathrm{O}$ 5 , Bulletin of Materials Science, 37(4), 843-848.

Panahi-Kalamuei, M., Alizadeh, S., MousaviKamazani, M., Salavati-Niasari, M. (2015). "Synthesis and characterization of $\mathrm{CeO}_{2}$ nanoparticles via hydrothermal route", Journal of Industria and Engineering Chemistry, 21, 1301-1305.

Ramesh, S., Raju, K. J. (2012). "Preparation and characterization of $\mathrm{Ce}_{1-} \mathrm{x}\left(\mathrm{Gd}_{0}\right.$ ${ }_{5} \mathrm{Pr}_{0.5)}{ }_{x} \mathrm{O}_{2}$ electrolytefor IT-SOFCs", International Journal of Hydrogen Energy, 37(13), 10311-10317.

Shuk, P., Wiemhöfer, H. D., Guth, U..., Göpel, W., Greenblatt, M. (1996). "Oxide ion conducting solid electrolytes based on $\mathrm{Bi}_{2} \mathrm{O}_{3}$ ", Solid State Ionics, 89(3-4), 179-196.

Steele, B. C. (2000). "Appraisal of $\mathrm{Ce}_{1-}$ ${ }_{\mathrm{y}} \mathrm{Gd}_{\mathrm{y}} \mathrm{O}_{2-}$ y/2electrolytesfor IT-SOFC operation at $500^{\circ} \mathrm{C}^{\prime \prime}$, Solid state ionics, 129(1-4), 95-110.

Stambouli, A. B., \&Traversa, E. (2002). "Solid oxide fuel cells (SOFCs): a review of an environmentally clean and efficient source of energy". Renewable and sustainable energy reviews, 6(5), 433-455.

Wang, X. W., Chen, J. G., Tian, Y. W., Wang, X. E., Zhang, B. H., Chang, X. H. (2016). "Lattice strain dependent on ionic conductivity of $\mathrm{Ce}_{0 .}{ }_{8+}{ }_{\mathrm{x}} \mathrm{Y}_{0 .}{ }_{2-}$ ${ }_{2 \mathrm{x}} \mathrm{Sr}_{\mathrm{x}} \mathrm{O}_{1} . \quad 9 \quad(\mathrm{x}=\quad 0-0.08)$ electrolyte", Solid StateIonics, 296, 85-89. 